\title{
Юрта как геометрическая модель в обучении математике в Туве
}
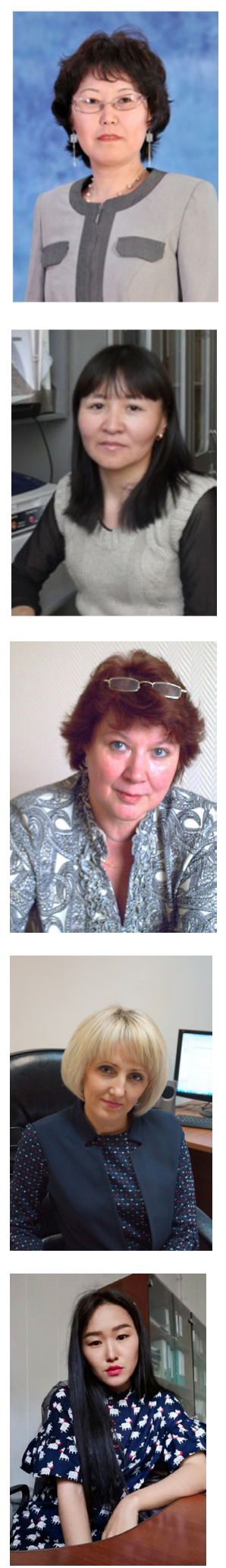

80

\author{
Менги В. Танзы, Сылдыс К. Саая \\ Тувинский государственный университет, Российская Федерация, \\ Виктория А. Шершнева, Юлия В. Вайнштейн \\ Сибирский федеральный университет, Российская Федерация, \\ Чодураа М. Ондар \\ Средняя общеобразовательная школа № 1 имени М. А. Бухтуева \\ 2. Кызыла, Российская Федерация
}

Статья посвящена пониманию юрты как модели при изучении аналитической геометрии в образовании Тувы (высшего и среднего уровней). В элементах юрты можно увидеть ряд геометрических фигур, поэтому она рассматривается как наиболее подходящая учебно-познавательная модель. Это имеет особый педагогический смысл, когда геометрические знания усваиваются в процессе исследования хорошо известного учащимся объекта.

Рассмотрены основные элементы юрты, в которых представлены формы всех трех геометрических тел вращения: цилиндра, усеченного конуса и части сферы, а также параллельные прямые, окружности, прямоугольники и другие.

Представлена авторская разработка - электронный обучающий модуль «Юрта как геометрическая модель при изучении математики». В него входят электронные интерактивные лекции, тесты-тренажеры и индивидуальные задания, позволяющие повысить качество математической подготовки и на практике продемонстрировать возможности электронного обучения.

Ключевые слова: юрта; тувинская юрта; тувинцы; Тува; математика; обучение математике; аналитическая геометрия; тело вращения; геометрическое понятие; геометрическая модель; электронная информационно-обучающая среда
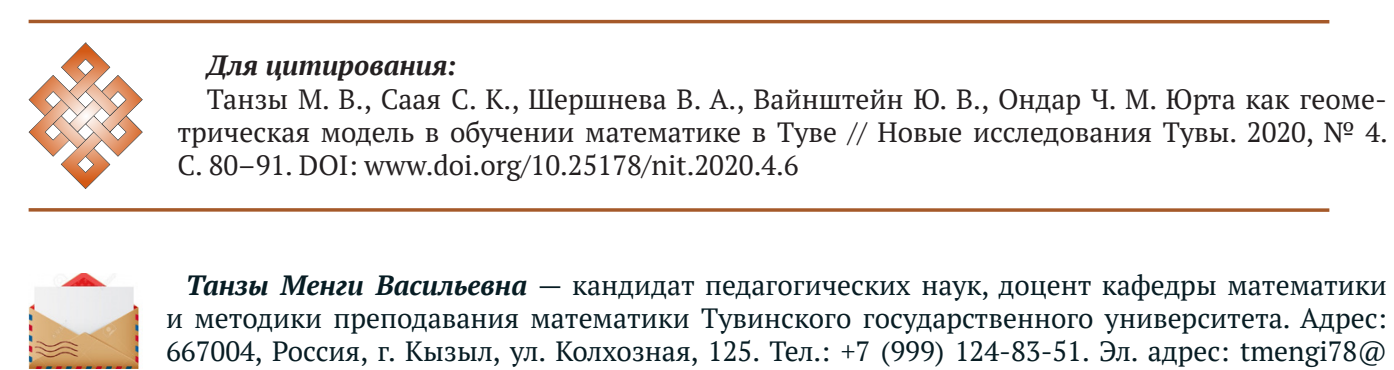

Танзы Менги Васильевна - кандидат педагогических наук, доцент кафедры математики и методики преподавания математики Тувинского государственного университета. Адрес: 667004, Россия, г. Кызыл, ул. Колхозная, 125. Тел.: +7 (999) 124-83-51. Эл. адрес: tmengi78@ mail.ru

Саая Сылдыс Казараковна - старший преподаватель кафедры математики и методики преподавания математики Тувинского государственного университета. Адрес: 667000, Россия, г. Кызыл, ул. Колхозная, д. 125. Эл. адрес: saaya@list.ru

Шершнева Виктория Анатольевна - доктор педагогических наук, профессор, профессор кафедры прикладной математики и компьютерной безопасности Сибирского федерального университета. Адрес: 660074, Россия, г. Красноярск, ул. Киренского, д. 26. Тел.: +7 (391) 291-27-90. Эл. адрес: vshershneva@sfukras.ru

Вайнштейн Юлия Владимировна - кандидат технических наук, доцент, доцент кафедры прикладной математики и компьютерной безопасности Сибирского федерального университета. Адрес: 660074, Россия, г. Красноярск, ул. Киренского, д. 26. Тел.: +7 (391) 291-27-90. Эл. адрес: yweinstein@sfu-kras.ru

Ондар Чодураа Мергеновна - учитель математики муниципального бюджетного образовательного учреждения «Средняя общеобразовательная школа № 1 имени М. А. Бухтуева» г. Кызыла. Адрес: 667000, Россия, г. Кызыл, ул. Кочетова, д. 59/3. Эл. адрес: onndarr@mail.ru 


\title{
The yurt as a geometric model in teaching mathematics
}

\author{
Mengi V. Tanzy, Syldys K. Saaya \\ Tuvan State University, Russian Federation, \\ Victoria A. Shershneva, Yulia V. Vainshtein \\ Siberian Federal University, Russian Federation, \\ Choduraa M. Ondar \\ Secondary school $N 1$ named After M. A. Bukhtuev, Kyzyl, Russian Federation
}

The article deals with the yurt as a model for the study of analytical geometry in the system of education of the Republic of Tuva. The elements of the yurt come as a number of geometrical shapes, such as a cylinder, a truncated cone and part of a sphere (the three main rotation bodies), as well as parallel lines, circles, rectangles, and other figures. Thus the yurt can be seen as the best study model for mastering geometrical knowledge by focusing on the object well-known to students.

The authors have developed an electronic training module titled "The yurt as a geometric model in the study of mathematics", working within a virtual learning environment. It includes interactive lectures, simulator tests and individual tasks, and aims to improve command of mathematics and demonstrate the potential of e-learning in practice.

Keywords: yurt; Tuvan yurt; Tuvans; Tuva; mathematics; teaching mathematics; analytical geometry; rotation body; geometrical concept; geometrical model; virtual learning environment

\section{For citation:}

Tanzy M. V., Shershneva V. A., Vainshtein Yu. V., Saaya S. K. and Ondar Ch. M. Iurta kak geometricheskaia model' $\mathrm{v}$ obuchenii matematike v Tuve [The yurt as a geometric model in teaching mathematics]. New Research of Tuva, 2020, no. 4, pp. 80-91. (In Russ.). DOI: www.doi.org/10.25178/nit.2020.4.6

TANZY, Mengi Vasilevna, Candidate of Pedagogy, Associate Professor, Department of the Mathematics and Methods of Teaching Mathematics, Tuvan State University. Postal address: 125 Kolkhoznaya St., 667004 Kyzyl, Russian Federation. Tel.: +7 (999) 124-83-51. E-mail: tmengi78@mail.ru ORCID ID: 0000-0001-5710-0676

SAAYA, Syldys Kazaracovna, Lecturer, Department of Mathematics and Methods of Teaching Mathematics, Tuvan State University. Postal address: 125 Kolkhoznaya St., 667004 Kyzyl, Russian Federation. E-mail: saaya@list.ru

ORCID ID: 0000-0003-3734-4424

SHERSHNEVA, Victoria Anatolyevna, Doctor of Pedagogy, Professor, Department of Applied Mathematics and Computer Security, Siberian Federal University. Postal address: 26 Kirensky St., 660074 Krasnoyarsk, Russian Federation. Tel.: +7 (391) 291-27-90. E-mail: vshershneva@yandex.ru ORCID ID: 0000-0002-9386-2018

VAINSHTEIN, Yulia Vladimirovna, Candidate of Technics, Associate Professor, Department of Applied Mathematics and Computer Security, Siberian Federal University. Postal address: 26 Kirensky St., 660074 Krasnoyarsk, Russian Federation. Tel.: +7 (391) 291-2790.E-mail: julia_ww@mail.ru ORCID ID: 0000-0002-8370-7970

ONDAR, Choduraa Mergenova, teacher of mathematics, Municipal Budgetary Educational Institution "Secondary school No. 1 named after M. A. Bukhtuev". Postal address: 59/3 Kochetov St., 667000 Kyzyl, Russian Federation. E-mail: onndarr@mail.ru 


\section{Введение}

Одним из важных принципов российской государственной политики в области образования является защита и развитие национальных культур, региональных культурных традиций и особенностей в условиях многонационального государства. Федеральный государственный образовательный стандарт высшего образования (ФГОС ВО 3++) для педагогических направлений подготовки ${ }^{1}$ определяет новые требования к обучению студентов - будущих учителей математики, которые должны овладеть системой математических знаний и умений и быть готовы к обучению школьников. При этом в процессе обучения в условиях Республики Тыва целесообразно не только повысить качество математической подготовки студентов за счет использования математических объектов, имеющих прикладной смысл и обладающих национальным, этническим колоритом, но и дать выпускникам - молодым специалистам возможность использовать опыт исследования таких объектов в дальнейшем при работе в различных школах республики, а также в других регионах для расширения кругозора школьников. Одним из важных разделов математики в вузе, который может опираться на этнический колорит, является аналитическая геометрия. При ее изучении у студентов развивается логическое мышление, воображение, пространственное представление, формируются профессиональные компетенции, которые необходимы будущим выпускникам педагогических направлений подготовки для обучения школьников геометрии.

Однако опыт авторов статьи при обучении студентов математике в Тувинском государственном университете показывает, что образовательные результаты студентов по аналитической геометрии остаются невысокими. Мы считаем, что это связано со сложностью курса «Аналитическая геометрия», в котором требуется иметь некоторые навыки пространственного представления. На изучение курса в вузе отводится 2-4 академических часа в неделю в течение первого семестра, всего от 36 до 72 часов. Очень мало рассматривается прикладных задач и наглядных объектов с этническим контекстом, поэтому весьма полезно включать в обучение студентов такие задачи и объекты, которые стимулируют познавательный интерес обучающихся (Монгуш, Танова, 2016).

Роль наглядности в обучении известна очень давно. Об этом писали многие педагоги-исследователи (Коменский, 1955; Леонтьев, 1959; Гильберт, Кон-Фоссен, 1936). Наглядность как один из основных принципов обучения развивает такие качества личности, как культуру мышления, творческое начало, интерес к изучаемому предмету. При изучении математики (в том числе и геометрии), в силу ее высокого уровня абстракции, требуется подкрепление реальными примерами, геометрическими образами, в этом случае усвоение материала происходит быстрее и легче.

Как известно, школьный курс геометрии включает планиметрию и стереометрию. Планиметрия посвящена изучению свойств фигур на плоскости, а стереометрия - свойств пространственных фигур, таких, как параллелепипед, шар, цилиндр, пирамида, конус и др. К основным задачам обучения геометрии в школе относятся изучение формы тела, изображение геометрических фигур и тел на плоскости, развитие пространственного мышления, формирование способности анализировать, рассуждать, доказывать. Объективно существующие предметы, хорошо воспринимаются, так как позволяют создать в голове наглядный образ (Волович, 1995). Поэтому, чтобы научить школьников понимать и любить геометрию, необходимо, чтобы студенты - будущие учителя математики владели не только предметом, но и могли показывать примеры на объектах, реально существующих в жизни и, возможно, имеющих значение для конкретной культуры (Аргунова, Аргунова, Попова, 2020; Солпубашова, Син, Мурзаибраимова, 2017; Кудрявцева, Удлер, 2015).

Целью данной работы является изучение учебно-познавательной математической модели в курсе аналитической геометрии традиционного жилья кочевников - юрты, объединяющей все три тела вращения: цилиндр, усеченный конус и части сферы. Изучение юрты как средство приобщения к народной культуре активно представлено в исследованиях (Какаева, Султанбаева, 2019; Вайнштейн, 1991, 2016; Байыр-оол, 2013; Донгак, 2012; Ондар, Танзы, 2016; Шойдук, 2019 и др. ${ }^{2}$. Тем не менее,

\footnotetext{
${ }^{1}$ Федеральный государственный образовательный стандарт по направлению подготовки 44.03.01 - Педагогическое образование [Электронный ресурс] // Портал федеральных государственных образовательных стандартов высшего образования. URL: http://fgosvo.ru/uploadfiles/FGOS\%20VO\%203++/Bak/440301_B_3_16032018.pdf (дата обращения: 01.09.2020).

${ }^{2}$ См. также: Дашеева, С. С. Математические задачи на основе фольклорного и краеведческого материала [Электронный ресурс] // Курсы для учителей. URL: https://multiurok.ru/index.php/files/matematicheskie-zadachina-osnove-folklornogo-i-kr.html (дата обращения: 01.09.2020).
} 
рассмотрение юрты как модели, которая может использоваться при изучении аналитической геометрии, в том числе с применением электронной среды - еще не осуществлялось. Эта цель решается в данной статье с применением электронной информационно-образовательной среды будущими учителями в вузе для обучения геометрии школьников.

Для достижения цели авторами ставятся следующие задачи: дать характеристику юрты как традиционного жилища в условиях кочевого быта, представить ее как математическую модель в обучении школьников и студентов геометрии и разработать элементы электронной информационно-обучающей среды для изучения геометрии юрты.

В настоящее время имеются новые возможности исследования геометрических объектов, которые связаны с электронным обучением: визуализация, анимация, электронные тренажеры и т. п. (Zykova et al., 2018; Танзы и др., 2019; Тарыма, Шершнева, Вайнштейн, 2019). По этой причине в электронных курсах по аналитической геометрии в вузе, а также геометрии в школе рассмотрение формы юрты имеет значительный дидактический потенциал.

В качестве источниковой базы исследования выступают опубликованные работы, которые рассматривают юрту как объект исторического наследия (Донгак, 2012; Какаева, Султанбаева, 2019; Ондар, Танзы, 2016; Потапов, 1969; Шойдук, 2019 и др.). Особую значимость имели материалы С.И. Вайнштейна, посвященные изучению культуры Тувы, открытию памятников различных периодов ее истории, где прошлое народа перекликается с его современностью (Вайнштейн, 1974, 1991, 2016). В работе также использована научно-учебная литература по обучению геометрии в школе и аналитической геометрии в вузе (Аргунова и др. 2020; Волович, 1995; Гильберт, Кон-Фоссен, 1936; Кудрявцева, Удлер, 2015; Монгуш, Танова, 2016). Привлечены научные статьи в области электронного обучения (Vainshtein et al., 2019; Zykova et al., 2018; Танзы и др., 2019; Тарыма и др. 2019), позволившие разработать электронный обучающий модуль «Юрта как геометрическая модель при изучении математики».

В процессе работы авторами проводился теоретический анализ обобщенного и собственного педагогического опыта обучения будущих учителей информатики и математики в Тувинском государственном университете, работы с абитуриентами на подготовительных курсах в рамках губернаторского проекта Республики Тыва «В каждой семье - не менее одного ребенка с высшим образованием», а также выездных работ в летнее время на чабанских стоянках при обучении школьников математике.

В качестве реального источника исследования выступают музейные экспозиции, хранящиеся в Национальном музее Республики Тыва (в т. ч. тувинская юрта).

\section{Юрта в условиях кочевого быта}

Юрта является важнейшим созданием культуры кочевников: казахов, киргизов, хакасов, алтайцев, бурят, монголов и многих других народов, занимающихся скотоводством, а также - тувинцев (Байыроол, 2013).

С. И. Вайнштейн называл юрту «замечательным изобретением», которое широко распространилось не только у кочевых народов степей, но вскоре проникло и к оседлым народам Китая и Японии (Вайнштейн, 2016: 221). Распространению ее у кочевых народов способствовала простота ее транспортировки, благодаря быстроте ее сбора за 1,5-2 часа и разбора в течение часа, а также возможности ее перевозки на лошадях и верблюдах в малодоступные ранее места, включая горные пастбища без применения громоздких повозок.

Тувинский народ сумел сохранить юрту в первозданном виде и до сих пор использует этот тип жилища для проживания на пастбищах в летнее и осеннее время года. Как писал С. И. Вайншейн, «еще рано заносить юрту в «красную книгу» (там же: 223).

Юрты сегодня стали также и частью этнокультурного туризма. Примечательными туристическими объектами выступают юрты, стоящие перед Национальным музеем им. Алдан-Маадыр Республики Тыва, в этнокультурном комплексе «Алдын-Булак» и в других туристических местах республики. В Туве и сегодня производят юрты, а также мебель для юрт. Например, изготовлением юрт занимаются Чаданский райпромкомбинат, ОАО «Юрта» города Чадан и другие организации и предприниматели.

У тувинцев юрта носит название өг - 'юрта' или кидис өг - ‘войлочная юрта'. Решетка юрты называется хана. Это слово проникло к тувинцам из монгольского языка, где хана означает решетку юрты. Обруч светодымового отверстия юрты известен у тувинцев как хараача и может быть сопоставлено с 
карак, означающим в ряде тюркских языков зрачок. К монгольскому языку восходят названия реек конического остова юрты - уна, ынаа (ср. монг. уни), войлок на куполе юрты - дээвиир (ср. монг. дээвэр).

Размер хана зависел от числа планок и от величины ячеек (хана карак, букв. - глаз хана). Так, самую маленькую ячейку, расстояние между углами которой было равно мугур сөөм ('малая пядь'), называли хураган карак - 'глаз ягненка', ячейку с размером узун сөөм - хой карак ('глаз овцы'), а ячейку, равную карыш - аът карак ('глаз лошади'). Количество хана определяло размер юрты, а степень их растяжки ее высоту.

Рассматривая числовые параметры некоторых элементов юрты, начнем с обруча светодымового отверстия диаметром 80-100 см, состоящего из толстой палки, согнутой в круг и четырех или шести согнутых в дугу, крестообразно перекрещивающихся тальниковых планок, образующих купол мөгеже.

Для цилиндрического остова юрты в зависимости от ее размеров предназначались три-четыре, реже пять полстей - aдаккы, привязывавшихся к остову юрты с помощью пришитых к углам волосяных веревок. Полсти дополнительно закрепляли на остове 2-4 сплетенными из волоса поясами кожалаң - шириной от 2 до 10 см и длиной от 6,7 до 20 м, черного, желто-серого, белого цвета, которые охватывали полсти и, опоясывая юрту, закреплялись концами к дверным косякам. Верхние полсти дополнительно фиксировались волосяными лентами (базырыг, или баглааш). Эти ленты (от 4 до 16 штук) крестообразно охватывали верхние полости и обычно закреплялись на нижних концах решетки (хана), реже их привязывали к лентам, опоясывающим решетку (Вайнштейн, 1991: 28).

Традиционная тувинская юрта имеет высоту 2,5 м, площадь около 19 м², вес около 350 кг.

С. И. Вайнштейн отмечал, что «все было в ней ориентировано по сторонам света, каждая вещь имела свою строго определенное место по отношению к входной двери, которая обычно была направлена на восток, реже - на юго-восток. Все детали юрты, выражаясь современным языком, унифицированы и могут быть легко заменены» (Вайнштейн, 2016: 230).

Внутреннее жилое пространство юрты условно разделялось на левую- мужскую и правую женскую половины. Напротив входа, в центре юрты находился очаг-одаг, который представлял собой семейный, хозяйственный и сакральный центр жилища. Он помещался в небольшой ямке на круглой, овальной или квадратной площадке, огороженной жердочками или камнями. Если вместо очага использовали печь, то круглую очажную площадку в юрте заменяли четырехугольной и располагали ее не в центре, а ближе к входу. Место вокруг очага носило название «край огня» - om кыдыь.

Небольшая площадь, прилегающая к двери, носила название эжик аксы - 'устье двери'. Далее стояли деревянные ведерки цилиндрической формы - хууњ, служившие подойниками, а также предназначавшимися для хранения воды. Березовые цилиндрические метровые долбленные бочки (доскаар) служили для кисломолочного напитка (хойтпак) или кумыса.

Напротив входа находилась почетная часть жилища дөр, где стояли парные деревянные ящики сундуки (anmapa), с открывающейся верхней крышкой и украшенные узорной росписью. Количество их могло доходить до шести и даже восьми, что свидетельствовало о состоятельности их владельцев. Рядом с ними располагались низенькие комоды (щургуулда), а поверх - шкатулки (хааржак). Средняя часть дор была наиболее почетной - дөр бажы (бажы - букв. 'голова') между средними аптара стояли невысокие квадратные или овальные столики - алтари (ширээ) высотой 20-25 см, с четырьмя или восемью ножками. На ширээ устанавливали буддийские культовые предметы, возлагали жертвоприношения.

На некотором расстоянии от дөр на левой стороне стояла кровать (орун), весила она всего несколько килограммов. На нее стелили большое количество матрацев (6-8) в зависимости от благосостояния семьи. В изголовье лежала валиковая подушка (cыpmык), лицевая сторона которой изготавливалась из прямоугольной дощечки и декорировалась кожей или тканью. В этой же части юрты висела деревянная колыбель (кавай), украшенная резными узорами. Далее шло место хозяйки у передней части матраца, лежащего на кровати, дөжек баары (дөжек - войлочный матрац), за ним дөжек адаa, что означало 'нижняя часть матраца'. Далее у кровати обычно располагали сундук для продуктов (буm anmapa), а рядом с ним полусферический чугунный котел (паш). За ним стояла этажерка үлгүүр с полками для посуды (Ондар, Танзы, 2016; Донгак, 2012 и др.).

Свободное пространство вокруг очага застилали войлочными стегаными ковриками - ширтек. Они декорировались различными стегаными узорами и имели трапециевидную форму, редко сег- 
ментовидную или квадратную, с дугообразной стороной относительно стены жилища (Шойдук, 2019: 312). Их величина зависела от размеров юрты.

Так, юрту можно рассматривать как образец формирования пространственного мышления, который демонстрирует объекты геометрии в традиционном жилом помещении.

\section{Юрта как геометрическая модель}

Юрта является уникальным архитектурным сооружением, и как отмечалось выше, объединяет в себе формы всех трех геометрических тел вращения: цилиндра, усеченного конуса и части сферы.

Вместе с понятием «тела вращения» рассматриваются такие понятия как высота юрты (өгнуң бедии), ее основание (өг орну), радиус основания, образующие цилиндра, в качестве которых выступает высота стены юрты, образующие конуса - палки (ынаалар), а также ось и осевое сечение.

При обучении школьников и студентов этим понятиям целесообразно использовать иллюстративный материал, представленный в виде рисунков и моделей. Это позволяет формировать пространственные образы, распознавать геометрические тела по их элементам, определять в них различные плоские фигуры (отрезок, луч, параллельные прямые, треугольник, ромб, трапеция, особенно окружность и круг, вписанные многоугольники). Все эти фигуры можно продемонстрировать на схематической модели юрты (см. puc. 1).

Мы измерили деревянный каркас 6-стенной стандартной юрты из экспозиции Национального музея Республики Тыва. На одну стену (хана) приходится 34 планки разной длины, самая короткая имеет длину $27 \mathrm{~cm}$, а самая

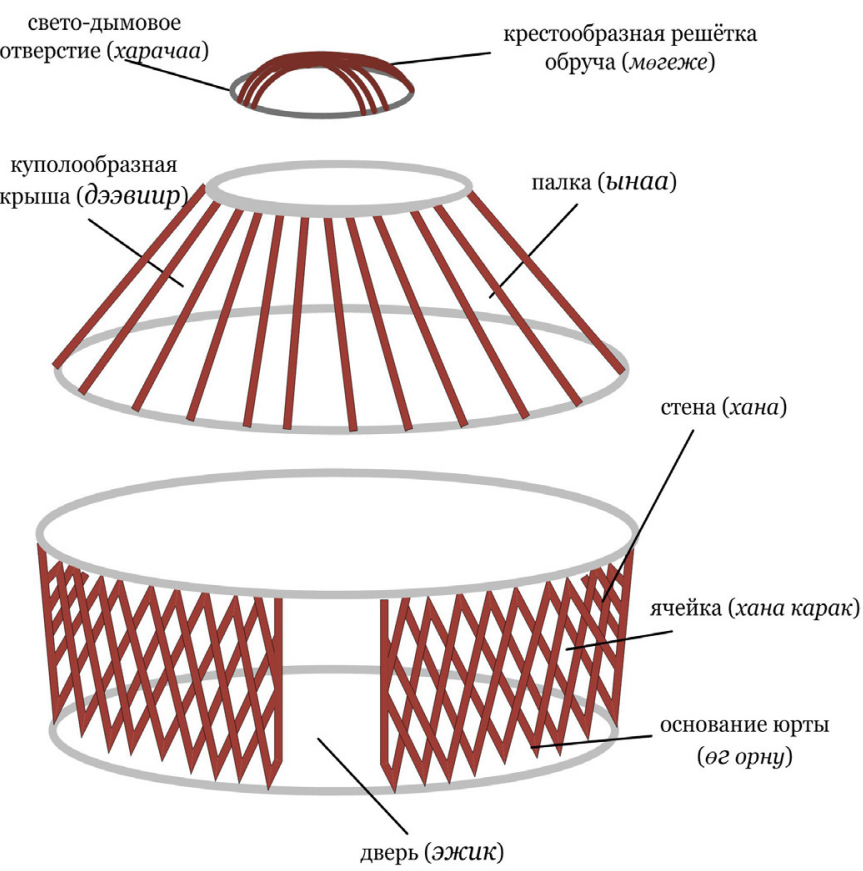

Рисунок 1. Модель юрты. Рисунок Ю. В. Вайнштейн. Fig. 1. A mode of the yurt. Drawing by Yu. V. Vainshtein. длинная $-186,5$ см. Размер хана зависит от числа планок и величины ячеек (хана карак). Расстояние между углами равно 19 см. Высота хана равна 140 см, ширина 250 см. (см. pис. 2).

Для конусовидной крыши юрты необходимы палки (ынаa), от количества стен юрты зависит и количество палок. На одну стену приходится 12 ынаа с длиной 200 см, на дверь стандартно приходится 5 ынаа.

Завершает конструкцию юрты светодымовое отверстие хараача, напоминающее окружность. Его размер определяют палки ынаа, увеличивается число палок и увеличивается диаметр окружности.

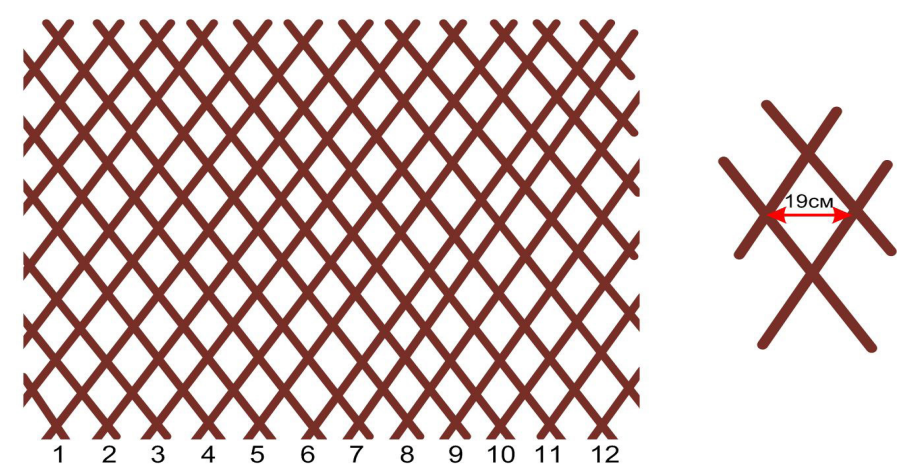

Рисунок 2. Одна из стен (хана) юрты. Рисунок Ю. В. Вайнштейн.

Fig. 2. One of the khana (walls) of the yurt. Drawing by Yu. V. Vainshtein. 
Внутренний диаметр равен 97 см и внешний диаметр равен 114 см (см. puc. 3).

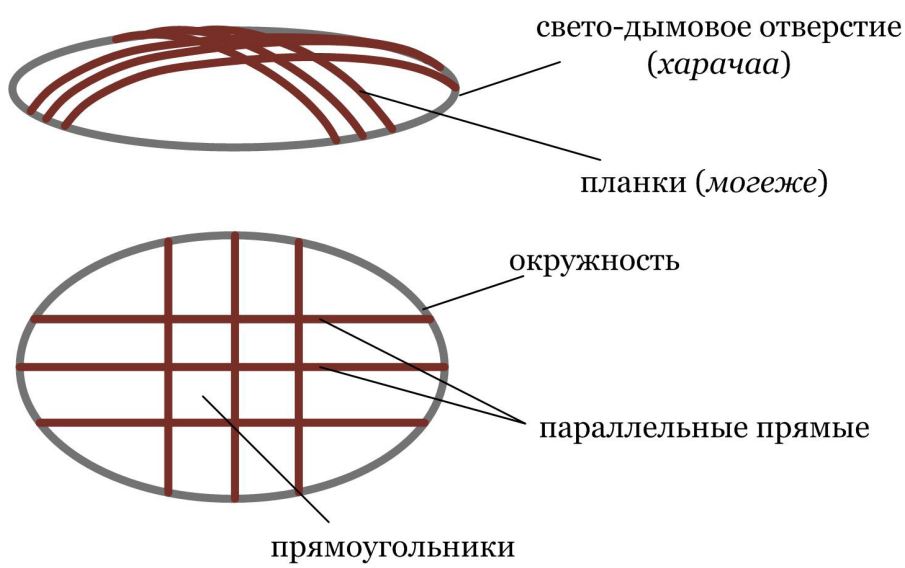

Рисунок 3. Хараача с мөгеже - полусфера. Рисунок Ю. В. Вайнштейн.

Fig. 3. Kharaacha and megazhe - a hemisphere. Drawing by Yu. V. Vainshtein.

Диаметр юрты -500 см, радиус - 250 см. Дверь эжик играет немаловажную роль в конструкции юрты, размер двери: высота - 140 см, ширина - 93 см.

С числовыми характеристиками юрты можно связать различные математические задачи. Например, задачи нахождения площади боковой поверхности юрты, длины окружности ее основания, объема цилиндрической части юрты, вычисления площади и объема юрт, имеющих различное количество стен: 4, 5 или 6. Повышение мотивации к изучению аналитической геометрии также вызывает задача нахождения количества войлока для покрытия нижней цилиндрической поверхности юрты (aдакы) в зависимости от количества стен или задача нахождения количества палок (ынаa) для юрты с 5, 6 или 9 стенами. Задачи с региональным контекстом стимулируют познавательный интерес обучающихся.

Особо следует отметить, что исторически первые меры длины у тувинцев, как у многих кочевых народов, выражали расстояние приблизительно в сравнении с частями человеческого тела. Например, при определении длины решеток и палок для юрты они использовали единицу измерения кулаш длину между вытянутыми горизонтально (на уровне плеч) руками взрослого человека, составляющую около 150 см; измерении окружности дымового круга - кулаш чартыы (половина кулаш) или төш чартыbl, равному расстоянию от грудной клетки до конца горизонтально вытянутой руки, примерно $75 \mathrm{~cm}$.

История развития единиц измерения у каждого народа имеет свои особенности. На занятиях со студентами - будущими учителями математики - можно провести исторический экскурс: все параметры юрты пересчитать в народных единицах, показать их связь с современными единицами измерения, тем самым вызвать интерес, повысить их мотивацию к изучению предмета, и конечно, в дальнейшем применить полученные знания в своей профессиональной деятельности.

\section{Применение электронной информационно-обучающей среды в изучении гео- метрии юрты}

Для повышения привлекательности решения представленных выше задач, а такжедля формирования у будущих учителей навыков создания элементов электронной информационно-обучающей среды в процессе их подготовки авторами статьи под руководством М. В. Танзы в электронной информационнообучающей среде разработан в 2020 г. электронный модуль «Юрта как геометрическая модель при изучении математики» (см. pис. 4). Он включает в себя электронные интерактивные лекции, тесты-тренажеры и индивидуальные задания, позволяющие повысить качество математической подготовки и на практике продемонстрировать возможности электронного обучения. Данный модуль планируется внедрить в учебный процесс в весеннем семестре 2020-2021 года в Тувинском государственном университете при обучении аналитической геометрии будущих учителей математики.

В качестве среды реализации электронного модуля была выбрана система управления электронного обучения LMS Moodle, которая широко распространена в образовательных учреждениях высшего образования и начинает активно использоваться и в школе. LMS MOODLE представляет собой систему 
дистанционного обучения с высокой степенью интерактивности и гибкости при создании цифрового обучающего контента.

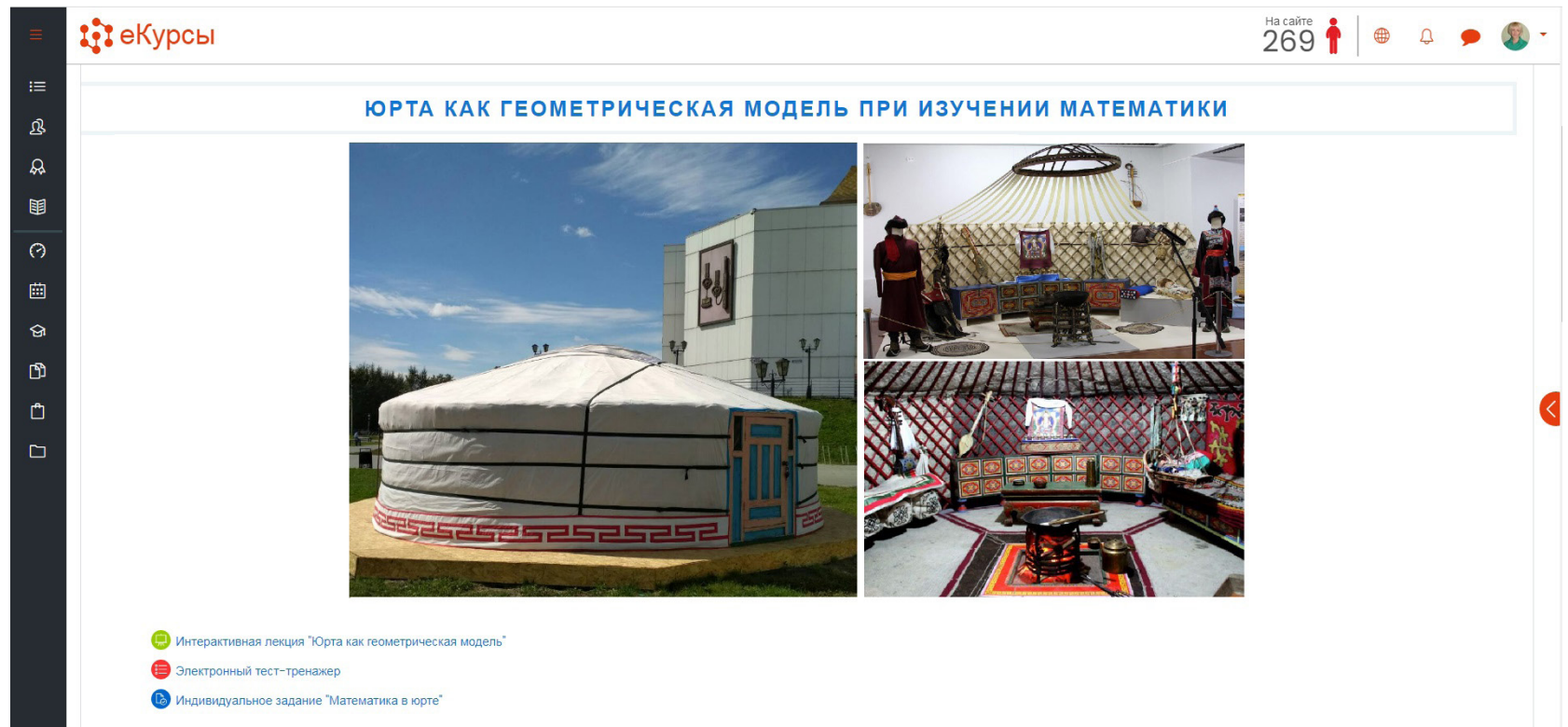

Рисунок 4. Фрагмент электронного-обучающего курса.

Fig. 4. Fragment of an electronic training course.

Интерактивная лекция разработана с применением элемента Moodle «Лекция». Учебный контент представлен в виде последовательно изложенного материала, разбитого на микропорции, контроль освоения которых осуществляется с применением тестовых заданий различных типов. В зависимости от результатов усвоения каждой микропорции студент переходит к следующему материалу (микропорции) или возвращается к предыдущему, а также может получить ссылки на дополнительный материал.

Цель интерактивной лекции данного модуля состоит в изучении юрты как геометрической модели. Студентам наряду с теорией предлагаются иллюстрации, рисунки и модели, формирующие пространственные образы и развивающие способности распознавать геометрические тела по их элементам. Они знакомятся с понятиями геометрических тел, поверхностей вращения, их характеристиками, изучают язык математики для записи и обработки результатов наблюдений и экспериментов.

Тесты-тренажеры направлены на закрепление визуального представления геометрических фигур, их понятий за счет установления соответствия с элементами каркаса юрты и ее внутреннего убранства. Рассмотрим пример тестового задания (см. puc. 5).

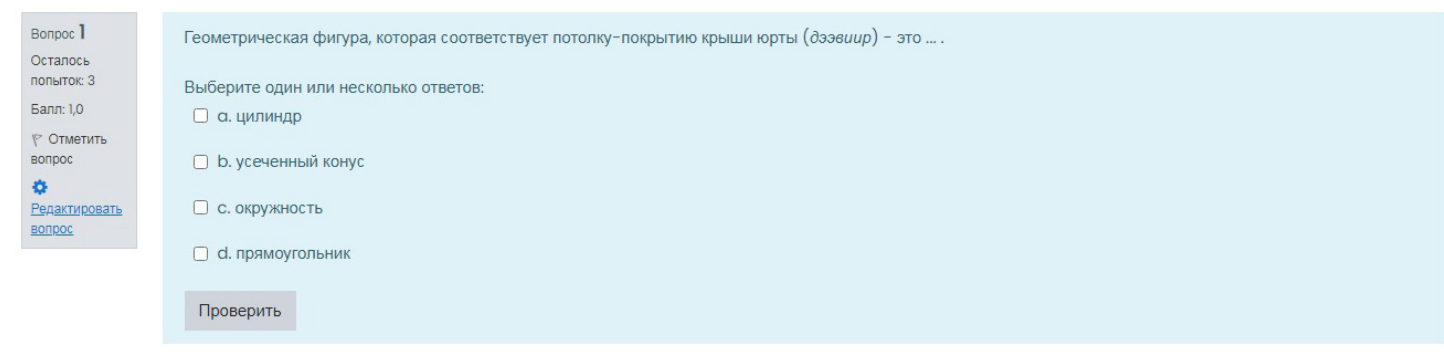

Рисунок 5. Пример тестового задания.

Fig. 5 A sample test question.. 
Для каждого вопроса предусмотрено несколько попыток. Если студент дает неправильный ответ, то ему дается первая подсказка - определения геометрических фигур (см. puc. 6). Повторив определения, можно ответить повторно, но с каждой попыткой количество баллов, получаемых за выполнение задания, уменьшается.

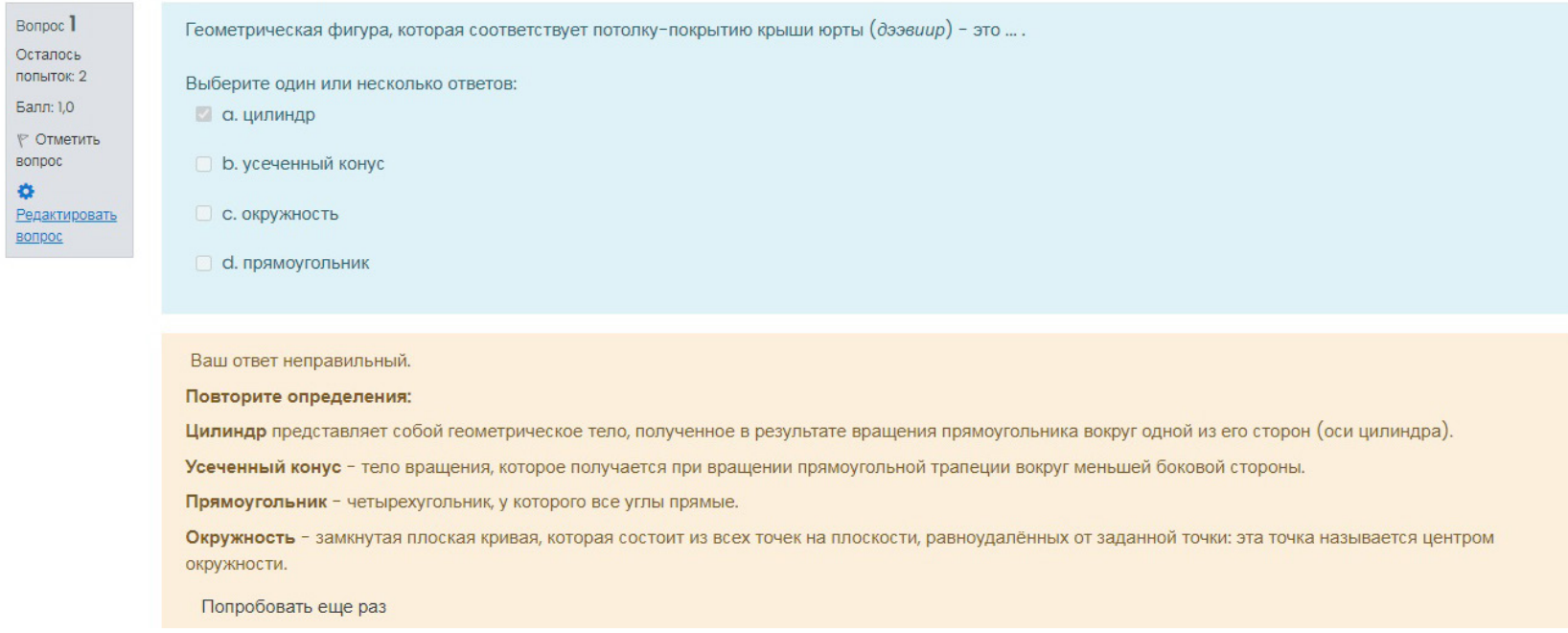

Рисунок 6. Первая подсказка.

Fig. 6 The first hint.

Если студент вновь дает неправильный ответ ему предлагается вторая подсказка (см. puc. 7).

\begin{tabular}{l} 
Вопрос 1 \\
Осталось \\
попыток: 1 \\
Балл: 1,0 \\
p Отметить \\
вопрос \\
क \\
Редактировать \\
вопрос \\
\hline
\end{tabular}
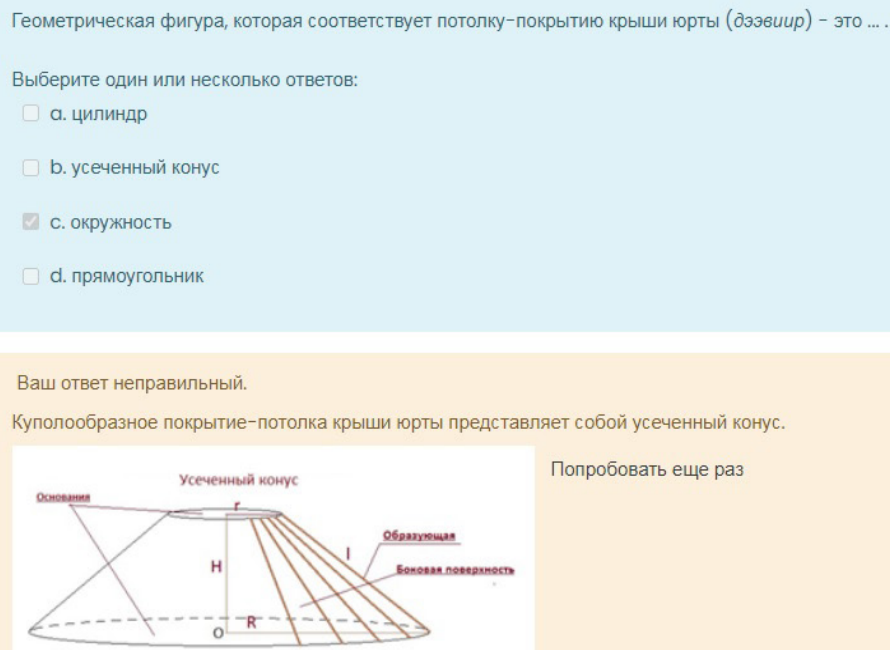
Попробовать еще раз

Рисунок 7. Вторая подсказка.

Fig. 7 The second tip.

После второй подсказки студент не получает баллов за правильный ответ на данный вопрос и переходит к следующему тестовому заданию, следующему элементу каркаса юрты или внутреннего ее убранства и закреплению соответствующего геометрического понятия. Таким образом, обучение 


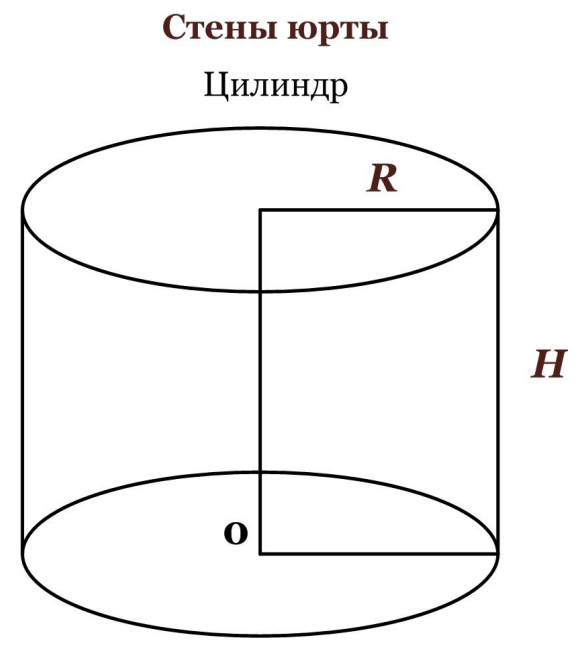

Рисунок 8. Схематическое изображение стен юрты. Рисунок Ю. В. Вайнштейн.

Fig. 8. A schematic representation of the walls of the yurt. Drawing by Yu. V. Vainshtein. усвоению геометрических понятий осуществляется многошагово при необходимости с возможностью использования нескольких попыток для каждого вопроса. Обучаемому всегда предоставляется возможность начать работу с тестомтренажером для улучшения своего образовательного результата.

Индивидуальныезадания сформулированыповариантам и направлены на проектирование будущими учителями математики собственных элементов электронной информационно-обучающей среды. Например, один из вариантов направлен на создание элемента электронной среды для решения школьниками следующей задачи и автоматизированной проверки полученного решения.

Задача: Найти площадь боковой поверхности юрты $\mathrm{S}_{\text {бок }}$. Построим геометрическую модель юрты (см. puc. 8), стены, которой, образуют цилиндр, радиус основания $R=260$ см, $H=170 \mathrm{cM}$.

Погружение задач с подобными примерами в электронную информационно-образовательную среду способствует формированию правильного понимания природы математики, повышения мотивации к изучению дисциплины, благодаря наглядной демонстрации ценности математического образования на практических примерах.

\section{Заключение}

Итак, юрту можно рассматривать как математическую модель в обучении аналитической геометрии будущих учителей. В ней множество геометрических объектов: цилиндр, усеченный конус, часть сферы, параллельные прямые, окружности, прямоугольники, ромбы, параллелепипеды, параллелограммы, трапеции.

Будущие учителя математики, сами изучая аналитическую геометрию на примере юрты и ее элементов, одновременно готовятся к тому, чтобы обучать школьников геометрии на знакомых предметах. Тем самым достигается особый эффект, если геометрические знания усваиваются в процессе исследования хорошо известного учащимся объекта, имеющего прикладной смысл и этнический колорит.

Результаты данного исследования могут быть распространены для обучения студентов инженерных направлений подготовки. Особенно это важно для обучающихся архитектурно-строительных направлений, которые могут использовать достоинства юрты в современных технологиях строительства, это касается ее конструкции, сохранения теплового баланса внутри юрты и другие. Юрту можно использовать как геометрический объект для знакомства дошкольников с азами геометрии, показать взаимосвязь природы с математикой, воспитывать у них наблюдательность, развивать любознательность, творчество. Юрта выступает как уникальный объект инженерной мысли и будет еще долго интересна исследователям для изучения ее с различных сторон, с точки зрения виртуального моделирования, антисейсмической устойчивости и другие.

\section{СПИСОК ЛИТЕРАТУРЫ}

Аргунова, Н. В., Аргунова, А. П., Попова, А. М. (2020) Развитие пространственного мышления обучающихся при решении геометрических задач с элементами якутского быта и зодчества // Педагогика. Вопросы теории и практики. Т. 5. № 1. С. 17-21. DOI: https://doi.org/10.30853/pedagogy.2020.1.3

Байыр-оол, М. С. (2013) Юрта в тувинской традиционной культуре [Электронный ресурс] // Новые исследования Тувы. № 2 (18). С. 67-79. URL: https://nit.tuva.asia/nit/article/view/242 (дата обращения: 20.09.2020).

Вайнштейн, С. И. (1974) История народного искусства Тувы. М. : Наука. 224 с.

Вайнштейн, С. И. (1991) Мир кочевников центра Азии. М. : Наука. 296 с. 
Вайнштейн, С. И. (2016) Загадочная Тува. Абакан : ООО «ИПП «Журналист». 416 с.

Волович, М. Б. (1995) Наука обучать: технология преподавания математики. М. : LINKA-PRESS. 280 с.

Гильберт, Д., Кон-Фоссен, С. (1936) Наглядная геометрия. М. ; Л. : ОНТИ. 304 с.

Донгак, С. Ч. (2012) Некоторые представления тувинцев, связанные с юртой. Древняя история и традиционная культура // Научное обозрение Саяно-Алтая. № 1 (13). С. 63-67.

Какаева, И. В., Султанбаева, К. И. (2019) Ознакомление с юртой как средство приобщения детей старшего дошкольного возраста к народной культуре хакасов [Электронный ресурс] // Интернаука. № 21-1 (103). C. 71-72. URL: http://internauka.org/journal/science/internauka/103 (дата обращения: 20.09.2020).

Коменский, Я. А. (1955) Избранные педагогические сочинения. М. : Рипол Классик. 651 с.

Кудрявцева, В. И., Удлер, Е. М. (2015) Вывод уравнения меридиана кругового тентового шатра // Фундаментальные исследования. № 7-2. С. 318-322.

Леонтьев, А. Н. (1959) О механизме чувственного отражения // Вопросы психологии. № 2. С. $19-41$.

Монгуш, А. С., Танова, О. М. (2016) Математические задачи с региональным контекстом как средство мотивации обучения математике (на примере республики Тыва) // Вестник Красноярского государственного педагогического университета им. В. П. Астафьева. № 2 (36). С. 22-27.

Ондар, Ч. М., Танзы, М. В. (2016) Юрта как один из элементов при изучении основных геометрических понятий // Актуальные проблемы исследования этноэкологических и этнокультурных традиций народов СаяноАлтая» : материалы IV международной научно-практической конференции молодых ученых, аспирантов и студентов, посвященная Году гостеприимства в Республике Тыва. Тувинский государственный университет / отв. ред. У. В. Ондар. Кызыл : Тувинский государственный университет. 227 с. С. 127-129.

Потапов, Л. П. (1969) Очерки народного быта тувинцев. М. : Наука. 303 с.

Солпубашова, А. Р., Син, Е. Е., Мурзаибраимова, Б. Б. (2017) Развитие познавательного интереса учащихся при изучении физики и математики // Известия Кыргызской Академии образования. № 1 (41). С. 66-72.

Танзы, М. В., Куулар, Л. Л., Троякова, Г. А., Саая, С. К. (2019) Технология дистанционного обучения математике студентов в электронной среде MOODLE// Вестник Красноярского государственного педагогического университета им. В. П. Астафьева. № 1 (47). С. 35-41. DOI: https://doi.org/10.25146/1995-0861-2019-47-1-101

Тарыма, А. К., Шершнева, В. А., Вайнштейн, Ю. В. (2019) Формирование информационно-коммуникационной компетентности будущего учителя республики Тыва в условиях двуязычия // Перспективы науки и образования. № 4 (40). C. 77-90. DOI: https://doi.org/10.32744/pse.2019.4.7

Шойдук, Л. Ш. (2019) Юрта - древнее жилище тувинцев // Искусство Евразии. № 3 (14). С. 302-316.

Vainshtein, I. V., Shershneva, V. A., Esin, R. V., Noskov, M. V. (2019) Individualisation of Education in Terms of E learning: Experience and Prospects // Journal of Siberian Federal University. Humanities \& Social Sciences. Vol. 9 (12). P. 1753-1770. DOI: https://doi.org/https://doi.org/10.17516/1997-1370-0481

Zykova, T. V., Shershneva, V. A., Vainshtein, Yu. V., Danilenko, A. S., Kytmanov, A. A. (2018) E-learning courses in mathematics in higher education // Perspectives of Science and Education. Vol. 4 (34). P. 58-65. DOI: https://doi. org/10.32744/pse.2019.4.7

Дата поступления: 20.09.2020 г.

\section{REFERENCES}

Argunova, N. V., Argunova, A. P. and Popova, A. M. (2020) Razvitie prostranstvennogo myshleniia obuchaiushchikhsia pri reshenii geometricheskikh zadach s elementami iakutskogo byta i zodchestva [Development of students' spatial thinking in solving geometric problems containing elements of Yakut life and architecture]. Pedagogika. Voprosy teorii i praktiki, vol. 5, no. 1, pp. 17-21. (In Russ.). DOI: https://doi.org/10.30853/pedagogy.2020.1.3

Baiyr-ool, M. S. (2013) Iurta v tuvinskoi traditsionnoi kul'ture [The yurt in traditional Tuvan culture]. New Research of Tuva, no. 2, pp. 67-79 [online] Available at: https://nit.tuva.asia/nit/article/view/242 (access date: 01.07.2020).

Vainshtein, S. I. (1974) Istoriia narodnogo iskusstva Tuvy [History of folk art in Tuva]. Moscow, Nauka. 223 p. (In Russ.).

Vainshtein, S. I. (1991) Mir kochevnikov tsentra Azii [The world of nomads of the center of Asia]. Moscow, Nauka. 296 p. (In Russ.).

Vainshtein, S. I. (2009) Zagadochnaia Tuva [The mysterious Tuva]. Moscow, Domashniaia gazetaю 416 p. (In Russ.) 
Volovich, M. B. (1995) Nauka obuchat': tekhnologiia prepodavaniia matematiki [The science of teaching: the technique of teaching mathematics]. Moscow, LINKA-PRESS. 280 p. (In Russ.).

Hilbert, D. and Cohn-Fossen, S. (1936) Nagliadnaia geometriia [Visual geometry]. Moscow, Leningrad, ONTI. 304 p. (In Russ.).

Dongak, S. Ch. (2012) Nekotorye predstavleniia tuvintsev, sviazannye s iurtoi. Drevniaia istoriia i traditsionnaia kul'tura [Some Tuvan concepts associated with the yurt: Ancient history and traditional culture]. Nauchnoe obozrenie Saiano-Altaia, no. 1 (13), pp. 63-67. (In Russ.).

Kakaeva, I. V. and Sultanbaeva, K. I. (2019) Oznakomlenie s iurtoi kak sredstvo priobshcheniia detei starshego doshkol'nogo vozrasta k narodnoi kul'ture khakasov [Getting familiar with the yurt as a means of introducing children of senior preschool age to the Khakass folk culture]. Internauka, no. 21-1 (103), pp. 71-72 [online] Available at: http:// internauka.org/journal/science/internauka/103 (access date: 20.09.2020). (In Russ.).

Komenský, J. A. (1955) Izbrannye pedagogicheskie sochineniia [Selected pedagogical works]. Moscow, Ripol Klassik. 651 p. (In Russ.).

Kudriavtseva, V. I. and Udler, E. M. (2015) Vyvod uravneniia meridiana krugovogo tentovogo shatra [Derivation of the eridian equation of a circular tent]. Fundamental'nye issledovaniia, no. 7-2, pp. 318-322. (In Russ.).

Leont'ev, A. N. (1959) O mekhanizme chuvstvennogo otrazheniia [On the mechanism of sensory reflection]. Voprosy psikhologii, no. 2, pp. 19-41. (In Russ.).

Mongush, A. S. and Tanova, O. M. (2016) Matematicheskie zadachi s regional'nym kontekstom kak sredstvo motivatsii obucheniia matematike (na primere respubliki Tyva) [Mathematical problems with a regional context as a means of motivating teaching mathematics: the case of the Republic of Tuva)]. Vestnik Krasnoiarskogo gosudarstvennogo pedagogicheskogo universiteta im. V. P. Astaf'eva, no. 2 (36), pp. 22-27. (In Russ.).

Ondar, Ch. M. and Tanzy, M. V. (2016) Iurta kak odin iz elementov pri izuchenii osnovnykh geometricheskikh poniatii [The yurt as an element in the study of basic geometric concepts]. In: Aktual'nye problemy issledovaniia etnoekologicheskikh $i$ etnokul'turnykh traditsii narodov Saiano-Altaia [Urgent issues of researching ethnoecological and ethno-cultural traditions of the Sayano-Altai peoples] : Proceedings of the $4^{\text {th }}$ international research and practical conference of young scientists, postgraduates and students dedicated to The year of hospitality in the Republic of Tuva / ed. by U. V. Ondar. Kyzyl, Tuvinskii gosudarstvennyi universitet. 227 p. Pp.127-129. (In Russ.).

Potapov, L. P. (1969) Ocherki narodnogo byta tuvintsev [The Tuvans: sketches of the folk lifestyle and related household activities]. Moscow, Nauka, GRVL. 402 p. (In Russ.).

Solpubashova A. R., Sin E. E. and Murzaibraimova B. B. (2017) Razvitie poznavatel'nogo interesa uchashchikhsia pri izuchenii fiziki i matematiki [Development of students ' cognitive interest in studying physics and mathematics]. Izvestiia Kyrgyzskoi Akademii obrazovaniia, no. 1 (41), pp. 66-72. (In Russ.).

Tanzy M. V., Kuular L. L., Troiakova G. A. and Saaia S. K. (2019) Tekhnologiia distantsionnogo obucheniia matematike studentov v elektronnoi srede MOODLE [Technology of distance learning in mathematics for students in the MOODLE virtual environment]. Vestnik Krasnoiarskogo gosudarstvennogo pedagogicheskogo universiteta im. V. P. Astaf'eva, no. 1 (47), pp. 35-41. (In Russ.). DOI: https://doi.org/10.25146/1995-0861-2019-47-1-101

Taryma, A. K., Shershneva, V. A. and Vainshtein, Yu. V. (2019) Formirovanie informatsionno-kommunikatsionnoi kompetentnosti budushchego uchitelia respubliki Tyva v usloviiakh dvuiazychiia [Building information and communication competence of teachers in the Republic of Tuva under conditions of bilingualism]. Perspektivy nauki i obrazovaniia, no. 4 (40), pp. 77-90. (In Russ.). DOI: https://doi.org/10.32744/pse.2019.4.7

Shoiduk, L. Sh. (2019) Iurta - drevnee zhilishche tuvintsev [The yurt as an ancient dwelling of Tuvans]. Iskusstvo Evrazii, no. 3 (14), pp. 302-316. (In Russ.).

Vainshtein, I. V., Shershneva, V. A., Esin, R. V. and Noskov, M. V. (2019) Individualisation of Education in Terms of E learning: Experience and Prospects. Journal of Siberian Federal University. Humanities \& Social Sciences, vol. 9 (12), pp. 1753-1770. DOI: https://doi.org/https://doi.org/10.17516/1997-1370-0481

Zykova, T. V., Shershneva, V. A., Vainshtein, Yu. V. and Danilenko, A. S., Kytmanov, A. A. (2018) E-learning courses in mathematics in higher education. Perspectives of Science and Education, vol. 4 (34), pp. 58-65. DOI: https://doi. org/10.32744/pse.2019.4.7

Submission date: 20.09.2020. 